FINANÇAS

\title{
A bolha e a tormenta
}

milênio começou com recessão, atentados terroristas espeta-
culares e escândal os corporativos, como as fraudes contábeis
da Enron e da Worldcom. Nos EUA, a década de 1990 fora marcada pela escalada exagerada do preço das ações. A valorização do índice Nasdaq entre 1991 e 1999 alcançou quase 1000\%. Desde o início de 2000 até setembro de 2002, porém, o mesmo índice amargou uma perda de mais de $71 \%$. Com o estouro da bolha especulativa, o valor de mercado das empresas norte-americanas já encolheu US\$ 7,6 trilhões. Qual éo impacto dessa reação aos excessos dos anos 1990?

por Pedro Fachada Banco Central do Brasil

Mensagem sarcástica distribuída por e-mail: um investidor que no fim de 1999 optasse por comprar um estoque de cervejas, degustar o conteúdo e vender as latas vazias em um posto de reciclagem, estaria hoje em meIhores condições (financeiras, bem entendido) do que se tivesse investido em ações da AOL, Enron, Worldcom,
N ortel, Yahoo, Starmedia e muitas outras.

Esse é o triste retrato do colapso do mercado de ações iniciado em março de 2000. Como se chegou nesse estágio, sea década de 1990 foi marcada pela valorização sem precedentes dos preços das ações das companhias norte-americanas? Com efeito, não faltaram justificativas para a escalada 
do mercado acionário. Os motivos iam do excepcional aumento da produtividade à universalização do acesso dos investidores às bolsas e do "fim" da inflação a mudanças demográficas que favoreciam as aplicações em renda variável.

Mas quais as causas do boom que atingiu o mercado acionário norte-americano nos anos 1990? E o que provocou seu posterior colapso, que ainda castiga severamente os investidores? Embora o foco de nossa análise seja o mercado nos EUA, fenômeno semelhante tomou corpo nas economias européias e em diversos mercados emergentes, com duas ressalvas importantes: o Japão, país que experimentou sua própria bolha especulativa nos anos 1980 e atravessou a década posterior ajustando os preços dos ativos e saneando seu sistema bancário; e o Brasil, onde a trajetória do Ibovespa foi marcada pelas respostas da política econômica às sucessivas crises externas que nos abateram no período.

Ascensão e queda: a evolução do mercado de ações entre 1991 e 2002. Antes de analisar a recente performance do mercado acionário nosEUA, valea pena apresentar os principais índices de preços das ações: o Dow Jones Industrial, o Standard \& Poor's 500 e o Nasdaq Composto.

0 Dow Jones Industrial é o índice de preços de ações mais tradicional e mais divulgado pelos meios de comunicação, embora seja também o mais restrito. É integrado pela nata do mundo corporativo norte-americano, englobando 30 grandes empresas predominantemente negociadas na Bolsa de Valores de N ova York. Compõem o Dow Jones nomes como: General M otors, Citibank, M CDonald's, Disney, Microsoft e Boeing. É, portanto, um índice de preços de ações de primeira linha. Esses papéis somavam um val or de mercado de US\$2,4 trilhões no fim de setembro de 2002.

0 Standard \& Poor's 500 - S\& P 500 - éum índice mais amplo, composto por 500 companhias abertas, cujas ações são negociadas em bolsas de valores. Em setembro, sua capitalização de mercado alcançava US\$ 7,5 trilhões, aproximadamente três vezes o tamanho do Dow Jones. As empresas integrantes do S\& P 500 estão distribuídas por diversos setores de atividade, preponderando o segmento financeiro (81 empresas ou 20,4\% do índice), seguido dos setores de saúde, bens de consumo e tecnologia de informação.
Finalmente, o Nasdaq Composto - ou simplesmente Nasdaq - é um índice de preços de ações listadas na bolsa eletrônica, que concentra os negócios das empresas de tecnologia. Em setembro, compunham o Nasdaq 3.800 companhias com valor de mercado de US\$1,7 trilhão.

Embora os váriosíndices divirjam em função desua composição e metodologia, tendem a apresentar uma trajetória semel hante em médio prazo, a menos que ocorram mudanças nas condições da economia. Na prática, foi isso o que ocorreu na segunda metade dos anos 1990, com a revolução tecnológica e a valorização das ações das empresas "pontocom" e de telecomunicação.

A valorização do índice Nasdaq entre 1991 e 1999 alcançou incríveis $988,5 \%$, equivalentes a um retorno médio anual de 30,4\%. Essa alta foi particularmente acentuada entreo último trimestre de 1998 emarço de 2000. Em contraste, desde 0 início de 2000 até setembro de 2002, o N asdaq amargou uma perda de $71,2 \%$, recuando para o nível do segundo semestre de 1996. Essa correção de preços trouxe a rentabilidade média do índice no período 1991-2002 para patamares mais realistas ( $10,2 \%$ ao ano).

Observe 0 Gráfico do Nasdaq, abaixo: uma valorização de preços acentuada, rápida e aparentemente irracional seguida por uma queda vertiginosa, que queima a gordura acumulada. Desde a "crise das tulipas", na Holanda do século XVII, a literatura econômica está repleta de episódios de bolhas especulativas. $\mathrm{O} \mathrm{N}$ asdaq, examinado com o distanciamento de mais de dois anos de ajuste, é um caso típico.

O S\& P 500 mostrou uma valorização de 344,9\% entre 1991 e 1999, seguido de uma queda de 44,5\% de janeiro de

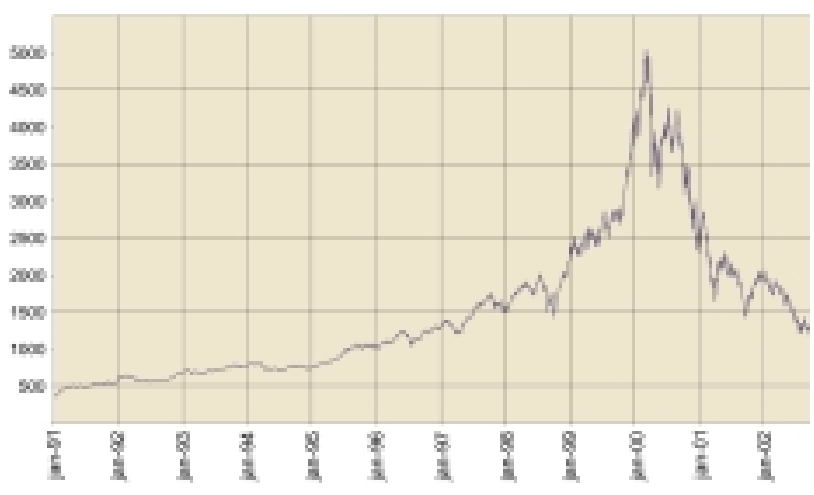

Gráfico - Índice Nasdaq (1991 - set.2002) Fonte: Nasdaq.com 
2000 a setembro de 2002. Quanto às empresas do Dow Jones, a performance nos anos 1990 foi similar à da carteira do S\& P 500. A devolução da alta pós-2000, entretanto, foi mais branda, com um recuo até setembro de $34 \%$. Não obstante, muitos investidores esperavam que as ações de primeira linha fossem "portos seguros" no caso de estouro da bolha tecnológica, o que não ocorreu.

0 valor de mercado das empresas é uma maneira alternativa de analisar o comportamento das bolsas de valores. Considerando uma estimativa ampla para cerca de 7 mil companhias abertas nos EUA, a desvalorização das ações entre março de 2000 e setembro de 2002 representou uma perda de riqueza de US\$ 7,6 trilhões. Em particular, o emagrecimento das empresas transacionadas na Nasdaq atingiu US\$ 5 trilhões no período. É importante reconhecer que se trata apenas de uma face da moeda, já que a valorização das ações nos anos 1990 "gerara" cerca de US\$13,5 trilhões.

Mas nada resume melhor a década de 1990 que a expressão "exuberância irracional", cunhada por Alan Greenspan em dezembro de 1996. Note-se que as magnitudes envolvidas (em comparação, o PIB norteamericano somou US\$10,1 trilhões em 2001) não deixam dúvidas quanto ao potencial impacto do desempenho das bolsas sobre o estado da economia.

A "nova economia" e o preço das ações. 0 desempenho do mercado acionário na segunda metade dos anos 1990 foi exagerado sob qualquer medida, com valorização muito acima do que se pode considerar razoável para o crescimento de longo prazo da economia, da produtividade e, possivelmente, dos lucros das empresas.

Existem várias abordagens para analisar o preço "correto" das ações, e esse é um campo extenso e controverso. Uma alternativa éa razão entre o preço elucro por ação - P/L. $0 \mathrm{P} / \mathrm{L}$ indica o tempo em anos que um investidor teria de permanecer com um título em sua carteira para recuperar o montante investido na forma de lucros.

Examinando em retrospectiva, as bolsas de valores atingiram, no fim da década passada, níveis de P/L muito acima de qual quer registro histórico. Entretanto, a evidência de um $\mathrm{P} / \mathrm{L}$ irrealista não chegou a contaminar a confiança dos investidores, dado o excepcional aumento da produtividade edas perspectivas de lucro no período.

0 debatesobrea "nova economia" centrou-se exatamente nesse ponto. 0 desenvolvimento da informática e a Internet trouxeram um sentido de "nova era" para a sociedade contemporânea, com o maior acesso à informação e abertura quaseilimitada de oportunidades. Empresas de comércio eletrônico e provedores de serviços para a Internet - como Amazon, AOL, Yahoo ou Ebay - saíram do papel e em poucos anos integravam a relação de maiores faturamentos dos Estados Unidos. Nesses segmentos, como no de telecomunicações, as empresas faziam grandes investimentos e abriam

\section{A valorização das bolsas nos anos 1990 criou} uma riqueza calculada em US\$ 13,5 trilhões. Ninguém resumiu melhor esse fenômeno que Alan Greenspan, que chamou a alta das ações de "exuberância irracional".

novos mercados, sendo compreensível que apresentassem resultados pífios ou mesmo negativos.

Por se basear em lucros históricos, portanto, o P/L não representava um paradigma para valorar as ações de tecnologia. Para o mercado, a abordagem mais adequada teria sido substituir o P/L pela relação preço/lucros futuros, o que implicava em projetar os resultados das empresas com um mínimo de consistência. Com isso, as estimativas irrealistas de lucros corporativos foram as grandes responsáveis pela exuberância irracional.

Outros fatores explicativos para a alta nas bolsas. Os benefícios da "nova economia" foram o grande motor da alta das ações durante a segunda metade dos anos 1990. Entretanto, outros elementos deram uma contribuição importante.

Em primeiro lugar, houve uma maior facilidade de acesso ao mercado. A segunda metade da referida década assistiu 
ao desenvolvimento de novas plataformas eletrônicas de negociação, que permitiram ao mercado acionário migrar do pregão tradicional para vias eletrônicas. As inovações nos sistemas eletrônicos facilitaram o acesso ao mercado por parte dos pequenos investidores, reduziram os custos de transação (corretagem), criaram o home broker, estenderam os horários de negociação com o pré e pós-mercado e popularizaram 0 day-trade.

0 boom do mercado de ações foi acompanhado por uma grande disseminação da indústria de fundos de renda variável. Igualmente importante foi a reforma no regime de aposentadorias para o sistema de contribuição e o crescimento da indústria de fundos de pensão. Tanto os fundos de renda variável como de pensão acrescentaram uma legião de investidores "indiretos" ao mercado.

Outra causa para o boom especulativo foi que, com a tendência de queda da taxa de inflação e a diminuição da taxa de juros nominal ao longo dos anos 1990, houve uma redução no custo de oportunidade das aplicações em renda variável. Além disso, em uma economia mais estável equeconferemaior segurança em relação ao futuro, os investidores apresentam maior propensão a ativos de risco. Baixas taxas de juros ealtos retornos nas bolsas também estimularam os norte-americanos a se endividarem para engordar seus portfolios.

Os analistas de Wall Street também colaboraram para o estado de otimismo por meio de suas avaliações das empresas. 0 economista Robert Shiller revela em seu livro Exuberância Irracional que no fim de 1999, quando o estouro da bolha era iminente, apenas $1 \%$ dos analistas de investimento aconselhavam seus clientes a vender ações.

Final mente, uma corrente de observadores explica a alta das bolsas na década de 1990 como resultado de fatores demográficos e comportamentais. Dentre eles, podemos citar uma menor aversão ao risco da geração nascida depois da 2a Guerra Mundial - os chamados baby boomers - , a generalização da prática de remunerar executivos por meio de opções de ações, uma confiança crescenteno modelo econômico norte-americano desde a queda do muro de Berlim e a maior aceitação social das oportunidades de jogo.

Os efeitos econômicos do crash. Em geral, os episódios históricos de bolhas especulativas não se caracterizam por uma reversão súbita da confiança ou por um ajuste instantâneo dos preços. 0 estouro da bolha da "nova economia" não é exceção, revelando-se um processo lento e contínuo. 0 ajuste foi precipitado pela decisão judicial no processo antitruste contra a Microsoft - março/abril de 2000 - , fato que suscitou uma série de incertezas sobre os lucros das empresas de tecnologia.

Na prática, a correção do preço das

\section{A redução da taxa de juros em 2001}

\section{aumentou o valor de mercado dos imóveis.}

\section{Essa estratégia contrabalançou a perda de}

\section{riqueza e o impacto recessivo provocados}

\section{pela queda das ações. Mas até quando?}

0 crescente interesse dos meios de comunicação pelas notícias financeiras foi outro fator que contribuiu para universalizar o mercado de ações. Os canais de televisão, incluindo as TVs por assinatura, foram os grandes veículos de divulgação do mercado. Sintomática dessa tendência foi a abertura de canais a cabo exclusivos para notícias econômicas e financeiras, como a TV Bloomberg. o superendividamento e o excesso de concorrência não foram acompanhados pel o crescimento da demanda, frustrando os resultados das empresas.

A queda nos lucros corporativos foi agravada pela recessão de 2001 epelo clima de instabilidade internacional e de maior aversão ao risco que se seguiu aos atentados terroristas de 
11 de setembro. Entretanto, o que de fato parece ter deteriorado a confiança dos investidores foram os escândal os corporativos que ocorreram desde o último trimestre de 2001: as fraudes contábeis da Enron e da Worldcom, as denúncias envolvendo uso de informação privilegiada por partedeexecutivos, o comprometimento das empresas de auditoria na chamada "contabilidade criativa" e o conflito de interesses entre as atividades de consultoria e os negócios próprios dos bancos de investimento. Assim, a "ganância infecciosa", segundo a expressão de Alan Greenspan, minou a credibilidade do mercado.

O dilema da correção deuma bolha especulativa é que os investidores "amadores" têm uma função de reação lenta à dinâmica do mercado. A captação dos fundos de ações, por exemplo, permaneceu positiva até $o$ inicio de 2002, atestando que os investidores de varejo mantiveram sua esperança na recuperação das bolsas mesmo após a eclosão dos escândalos corporativos. Esses investidores prova-

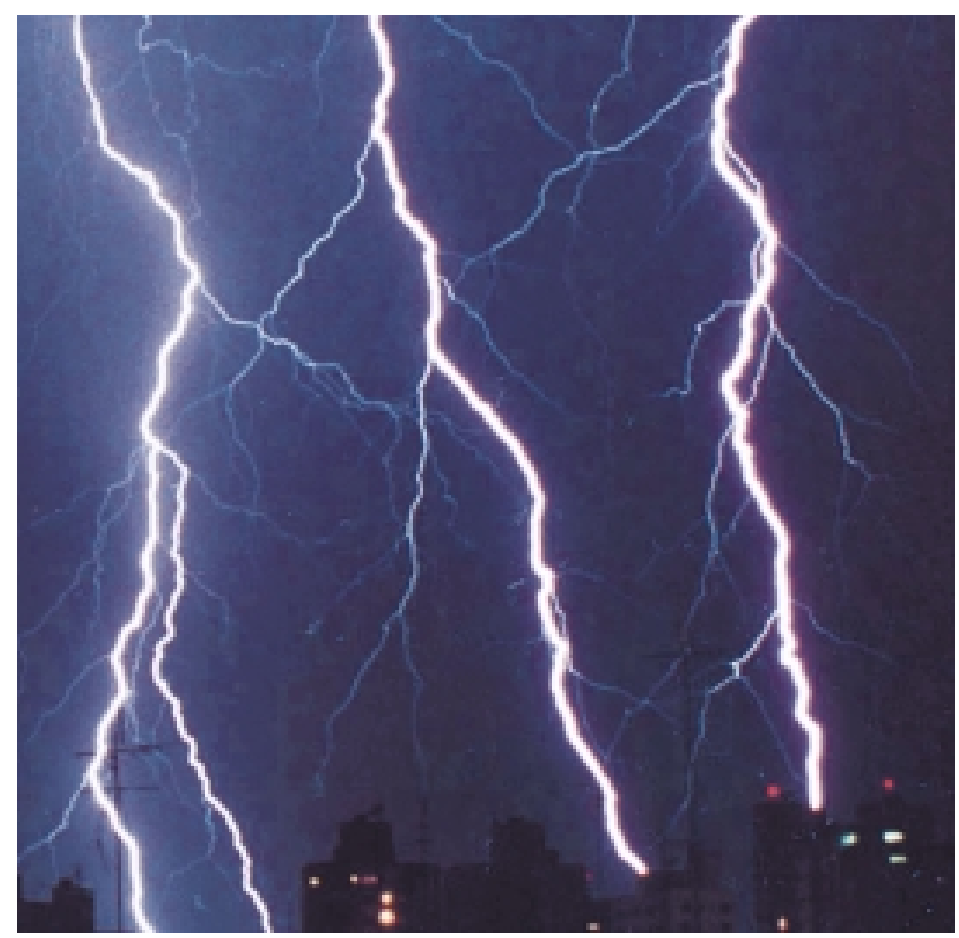
velmente entraram no mercado quando a bolha já estava formada e só reviram suas estratégias de investimento após largos prejuízos. Para eles, a aversão ao risco multiplicou-se, o que deve fazêlos ficar longe do mercado por vários anos. A aversão ampliada ao risco pode desencadear uma bolha invertida - correção exagerada do preço das ações - , antes que o mercado recobre sua trajetória de alta.

Qual o efeito do ajuste das bolsas sobre a economia? Mencionamos anteriormente que a queda das ações desde março de 2000 reduziu o valor de mercado das empresas norte-americanas em cerca de US\$ 7,6 trilhões. Essa perda é contabilizada pelo chamado "efeito riqueza", isto é, pelo impacto contracionista que a queda de riqueza financeira provoca sobre as decisões de consumo einvestimento. Segundo estimativas, esse efeito é da ordem de 3\% a $5 \%$.

De fato, a desaceleração da economia norte-americana no biênio 2001/2002 foi causada pela severa contração do investimento, após anos de expansão da capacidade produtiva motivada pelo baixo custo do capital no período da boIha financeira. Entretanto, a recessão foi amortecida pelo bom desempenho do consumo das famílias.

0 consumo tem resistido à queda das bolsas devido à política monetária expansionista seguida pelo Federal Reser-

ve - FED, o banco central norte-americano - desde 2001. Por meio da queda da taxa de juros, o FED procurou incentivar 0 investimento e principalmente criar um efeito compensatório para a perda de riqueza causada pelo colapso das bolsas. A redução da taxa de juros favoreceu a renda disponível das famílias com dívidas imobiliárias, incentivou o setor e gerou um aumento no preço dos imóveis, contrabalançando 0 ajuste do preço das ações.

Perspectivas. Até o momento, a estratégia do FED funcionou de forma exemplar. Seu maior risco é que a destruição de riqueza nas bolsas traga efeitos adversos retardados. Entre eles, o aumento da inadimplência seguido de uma crise bancária, ou o estouro de uma nova bolha - desta vez, do preço dos imóveis. Trata-se de um risco que já vem sendo chamado de "japanização" da economia norte-americana.

Para os investidores, as perspectivas para curto e médio prazo são pouco animadoras. Com efeito, não restam muitas opções além da torcida por um cenário internacional menos instável e por novas medidas de "resgate" por parte do FED embora seja difícil imaginar o que ainda possa ser feito pela autoridademonetária. Em comparação com a década anterior, os tempos hoje são de grande apreensão. 